\title{
Computational Study for the Evaluation of Drug Candidature of the Most Abundant Molecules from Vitex agnus-castus $L$. for Inhibition of HBV Capsid and X Proteins
}

\author{
Fatima-Ezzahra Eddaoudi ${ }^{1,2}$, Siham Mallouk ${ }^{1}$, Amine El Farrouji ${ }^{3}$, Brahim Boualy 1,*(D), Mohamed \\ Tabyaoui $^{2}$ \\ 1 Université Sultan Moulay Slimane, Faculté Polydisciplinaire de Khouribga, B.P : 145- 25000 Khouribga Morocco \\ 2 Laboratoire de Chimie Appliquée des Matériaux, Centres des Sciences des Matériaux, Faculty of Sciences, Mohammed V \\ University in Rabat, Avenue Ibn Battouta, BP 1014, Rabat, Morocco \\ 3 Lycée qualifiant Zerktouni, BP 2390, 40140 Marrakech, Morocco \\ * Correspondence: b.boualy@usms.ma;
}

Scopus Author ID 35317062400

Received: 28.02.2021; Revised: 20.04.2021; Accepted: 23.04.2021; Published: 8.05.2021

\begin{abstract}
Hepatitis B virus (HBV) infection is one of the main sources of liver disease. In this study, we use computation methods to evaluate the drug candidature of the most abundant molecules from Vitex agnus $L$ for the inhibition of $\mathrm{HBV}$ capsid protein and X protein. Molecular docking analyses were performed, using Autodock Vina, PKCSM and SwissADME were used to calculate ADMET. The results showed that the free binding energy for all tested molecules is better than that of Tenofovir disoproxil, a drug used to treat HBV, using capsid protein and protein $\mathrm{X}$ as a target. These results indicate that these ligands bind favorably to the binding site of HBV capsid protein and protein X, which may be considered a potential ligand for treating HBV-related diseases.
\end{abstract}

Keywords: hepatitis B virus; molecular docking; inhibitor; Vitex agnus-castus $L$.

(C) 2021 by the authors. This article is an open-access article distributed under the terms and conditions of the Creative Commons Attribution (CC BY) license (https://creativecommons.org/licenses/by/4.0/).

\section{Introduction}

Hepatitis B virus (HBV) infection is still a serious health threat worldwide [1]. It has become the most prevalent viral liver infection worldwide and is a major global health burden. According to The World Health Organization (WHO), more than 325 million people have viral hepatitis B (HBV), which is an infection that attacks the liver and results in acute or chronic infection of that organ with a rate of mortality of more than 887,000 deaths [2]. The prevalence of HBV in Morocco is evaluated at $1.81 \%$ [3, 4]; this value is lower than other countries of the Maghreb but remains important if one compares it with the developed countries [5-7]. Currently, two approved treatment strategies are available, pegylated interferon (PEG-IFN) or nucleos ( $\mathrm{t}$ ) ide (NA) analogs, which suppress HBV replication and slow disease progression. However, these treatments usually do not lead to a cure [8-10]. Therefore it is necessary to look for solutions to minimize this value.

Vitex agnus-castus L., commonly known as chaste berry, is a popular medicinal plant with recognized beneficial effects on human health, belonging to the Lamiaceae family, native to the Mediterranean area, and diffused in Europe, North Africa, and Asia. It has been used by people in Egypt, Greece, Italy, and Iran for over 2500 years, mainly to treat gynecologic 
disorders [11]. The fruits of Vitex agnus-castus have been used to treat several females' problems such as menstrual disorders, premenstrual symptoms, menopause, disrupted lactation, acne, corpus luteum insufficiency, and infertility [12]. Hot water extracts from the fruits and flowering tops are used as antispasmodic, sedative, and anaphrodisiac [13]. Moreover, it relieves headaches, syphilis, influenza, diarrhea, stomachache [14], toothache, and rheumatism [15]. In addition, this plant have hight number of biological proprieties including antitumoral ,antioxidant ,anti-inflammatory [16], antibacterial [9], and antifungal [17]. The richness of this plant in several molecules pushed us to make studies in silico of the most dominant compounds from Vitex agnus-castus $L$. with the HBV capsid, a stable polymer composed of 90 or 120 homo-dimers of the viral core protein, and it contains viral DNA and reverse transcriptase [18], in order to discover new natural molecules that can be used as inhibitors of HBV. The ADME properties of all ligands are also studied.

\section{Materials and Methods}

\subsection{Ligand preparation.}

Ten of the most abundant molecules from Vitex agnus-castus L. and Tenofovir disoproxil, a commercial drug for inhibition of $\mathrm{HBV}$, were selected to screen their potential inhibitory action against the hepatitis B virus. AutoDock Tools $[19,20]$, in default parameters, was used to prepare these ligands for docking.

\section{2. $H B V$ capsid protein preparation.}

In this study, the HBV capsid protein and protein $\mathrm{X}$ were chosen as targets. The structures of these proteins were obtained from the RCSB site (https://www.rcsb.org) (PDB ID of HBV capsid protein: $3 \mathrm{KXS}$, resolution of $2.25 \AA$, and the PDB ID of HBV protein X: $3 \mathrm{I} 7 \mathrm{H}$, resolution of $2.9 \AA$ ). And then, they are prepared for molecular docking using AutoDock Tools by removing water molecules, ions, and ligands. The addition of hydrogen atoms to the receptor molecule was done using MG Tools (AutoDock Vina) software [19,20]. The structures of proteins were then saved in PDBQT format for docking.

\subsection{Molecular docking.}

AutoDock Vina $[19,20]$ was used to predict binding affinities $(\mathrm{kcal} / \mathrm{mol})$ between HBV capsid protein and $\mathrm{HBV}$ protein $\mathrm{X}$, as targets, and ten of the most abundant molecules from Vitex agnus-castus $L$. in addition to Tenofovir disoproxil, a commercial drug of HBV, as a reference. The grid box size was set at $58 \AA$ for $\mathrm{x}, \mathrm{y}$, and $\mathrm{z}$, and the grid center was set to -9.88 $\AA,-27.39$, and 5.03 for $\mathrm{x}, \mathrm{y}$, and $\mathrm{z}$, respectively for the HBV capsid protein. For the $\mathrm{X}$ protein, the grid box size was set at $62 \AA$ for $\mathrm{x}, \mathrm{y}$, and $\mathrm{z}$, and the grid center was set to $14.52 \AA, 38.40$, and 40.73 for $\mathrm{x}, \mathrm{y}$, and $\mathrm{z}$, respectively.

\subsection{ADME calculations.}

PKCSM (pkCSM (unimelb.edu.au/) and SwissADME (https://swissmodel.expasy.org/) were used to calculate ADMET of the ten of the most abundant molecules from Vitex agnuscastus $L$. in addition to Tenofovir disoproxil. 


\section{Results and Discussion}

Our study aimed to identify alternative drugs against human HBV from natural products. A total of ten small molecules from Vitex agnus-castus L. were selected. These compounds, screened in silico, used in the study were further assessed on Lipinski's Ro5 formula and their physiochemical properties for drug-likeness.

\subsection{Molecular docking.}

The docking of the selected ligands with HBV proteins (capsid protein and protein X) as targets was performed using AutoDock Vina software. And the interactions in the complexes (protein-ligand), including hydrogen bonds and the bond lengths, were analyzed using Discovery Studio 2020 Client software. The results of this study are summarized in table 1. Once the docking search is complete, the best conformation corresponding to the lowest docked energy is chosen.

Table 1. Score of docking results and interactions protein-ligands.

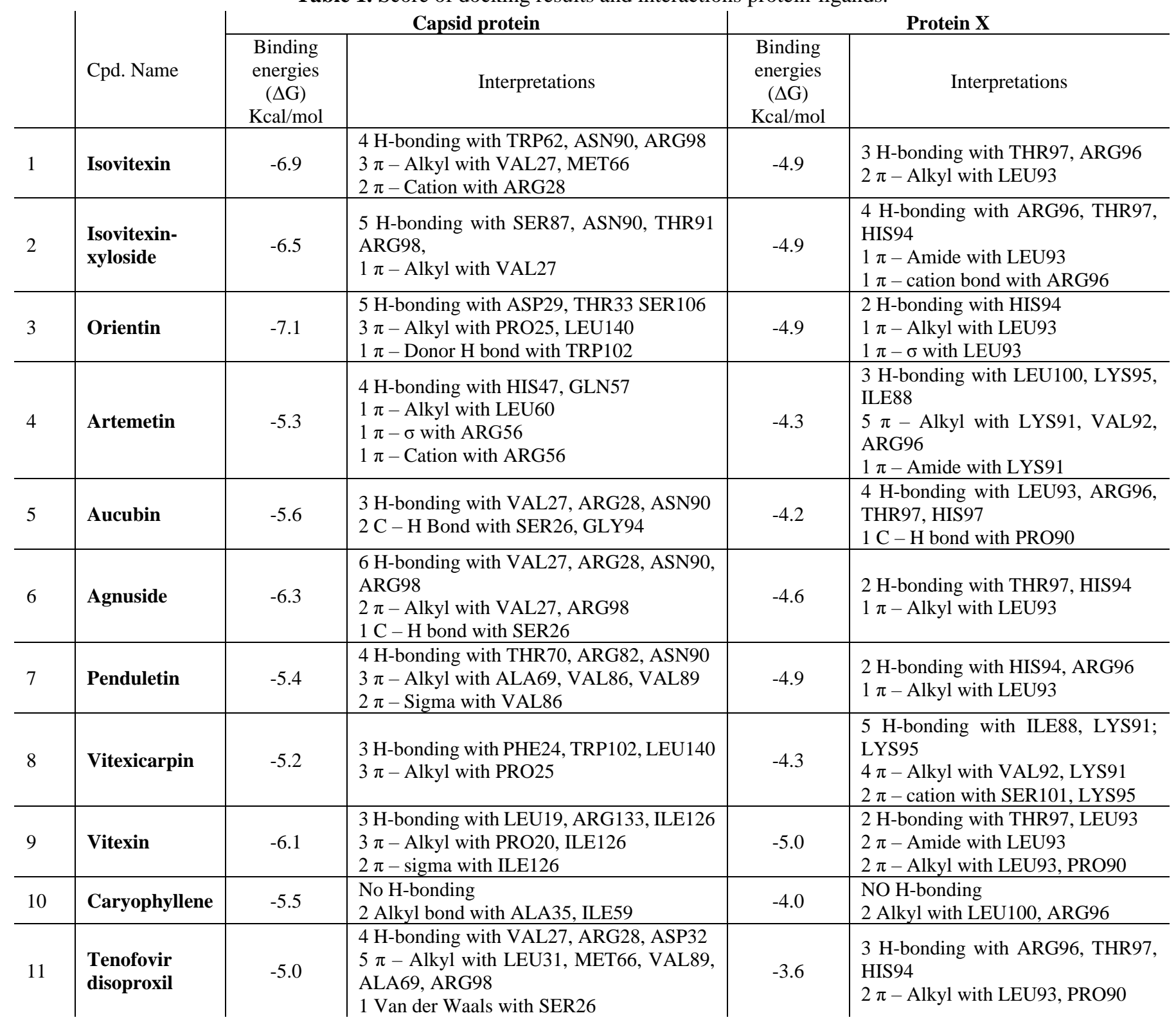


The analysis of molecular docking results (Table 1) show that the resulting afnity energies, an important indicator of the interaction between protein and ligand, are ranging from -7.1 up to $-5.0 \mathrm{kcal} / \mathrm{mol}$ for the capsid protein and from -5.0 up to $-3.6 \mathrm{kcal} / \mathrm{mol}$ for the protein $\mathrm{X}$ of the $\mathrm{HBV}$, which means that our ligands are very likely to have activity interaction with the capsid protein of the HBV. The bests results are obtained by Isovitexin and Orientin as ligands $(-6.9$ and $-7.1 \mathrm{Kcal} / \mathrm{mol})$ using the capsid protein as a target, better than Tenofovir disoproxil $(-5.0 \mathrm{Kcal} / \mathrm{mol})$, which is an approved drug used in the treatment of HBV. With protein $\mathrm{X}$ as a target, all ligands have a similar value of the binding energy which is better than Tenofovir disoproxil $(-3.6 \mathrm{Kcal} / \mathrm{mol})$. The difference in energy affinity can be explained by the ligand/protein interaction (table 1). As showed in Fig. 1 and Fig 2, the complexes between ligands and the receptors are mainly stabilized by hydrogen bonds, $\pi-\pi$ interactions, $\pi-$ Alkyl and $\pi-$ Cation.

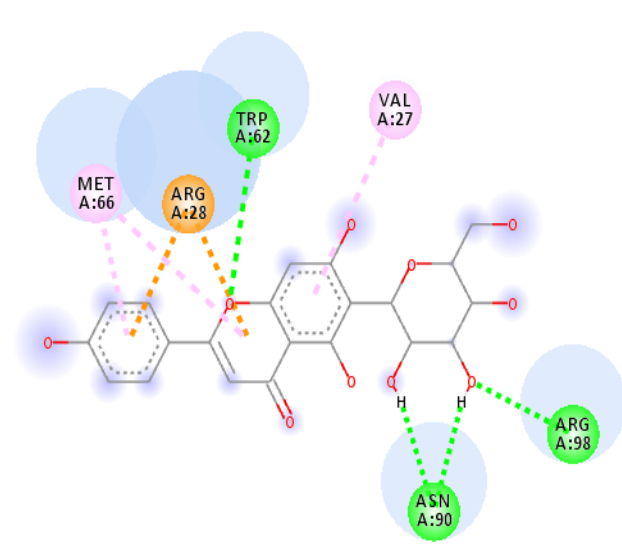

Isovitexin

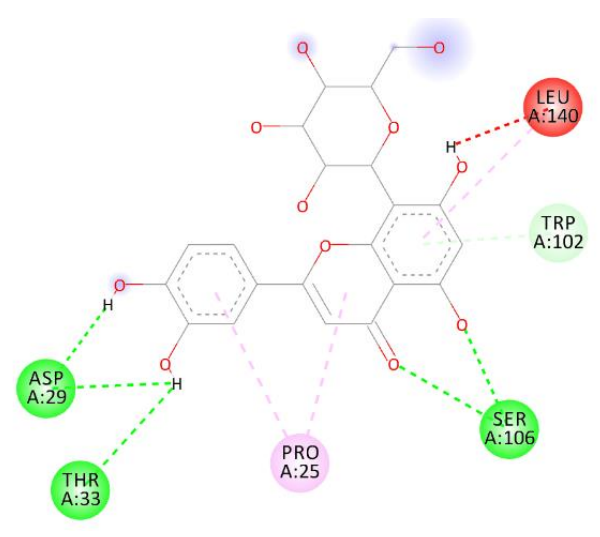

Orientin

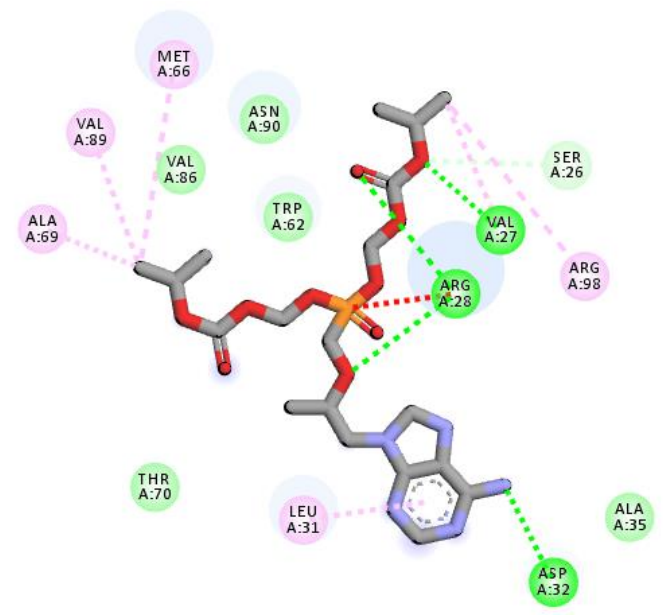

Tenofovir disoproxil

Figure 1. Interactions in capcide protein of HBV and Ligands complexes.

\subsection{Physicochemical properties ADME.}

The best ligands for inhibition of a protein can be selected based on their binding energy. Nonetheless, ADMET (Absorption, Distribution, Metabolism, Excretion, and Toxicity) properties are appropriate methodologies employed in the drug development and discovery process. The ADMET profile was analyzed for the selected compound to determine the nature of the drug's reactivity.

Table 2 lists each molecule's physiological properties like the hydrogen bond acceptor (nON), hydrogen bond donor (nOHNH), molecular weight, absorption, etc. 


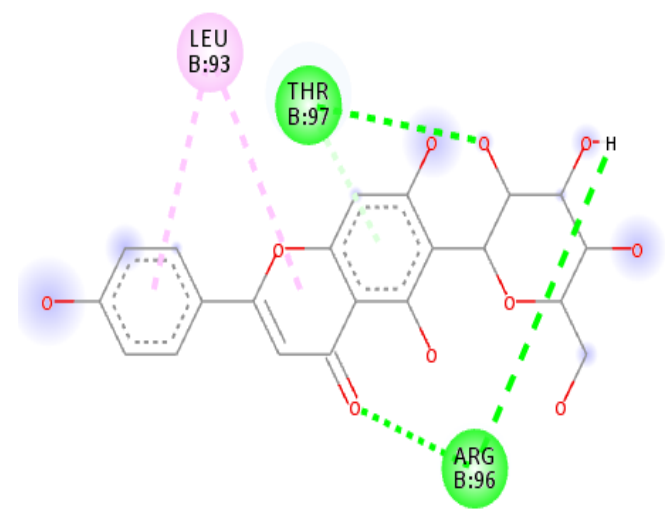

Isovitexin

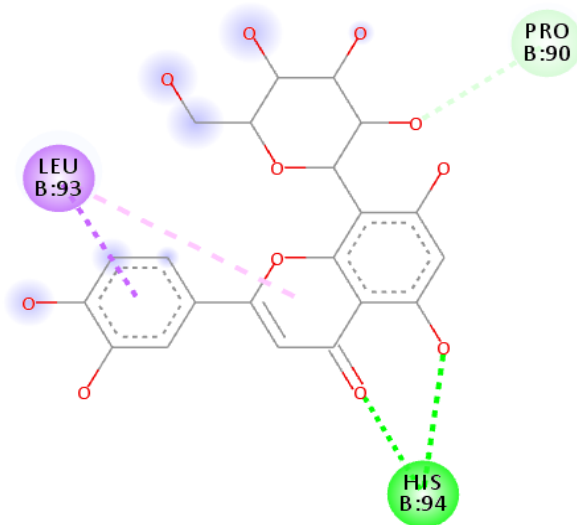

Orientin

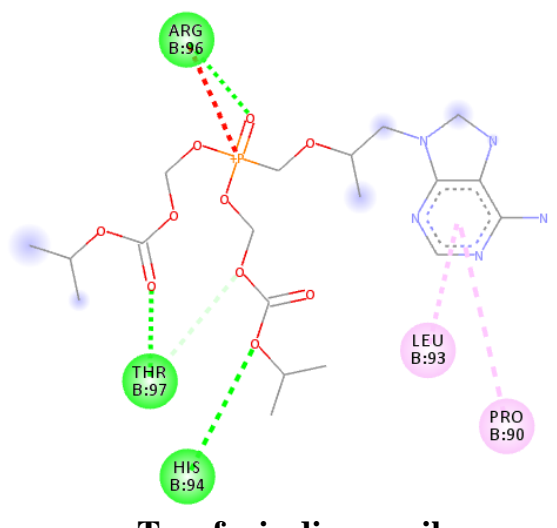

Tenofovir disoproxil

Figure 2. Interactions in protien $\mathrm{X}$ of HBV and Ligands complexes.

Table 2. Physicochemical properties (ADME).

\begin{tabular}{l|l|l|l|l|l|l|l|l} 
Ligand & $\mathbf{M W}(\mathbf{g} / \mathbf{m o l})$ & $\mathbf{n O N}$ & $\mathbf{n O H N H}$ & $\mathbf{n r o t b}$ & $\mathbf{T P S A}$ & $\mathbf{L o g P}$ & $\mathbf{L D} \mathbf{5 0} \mathbf{~ m g} / \mathbf{k g}$ & $\mathbf{n V i o}$. \\
\hline Isovitexin & 432.381 & 10 & 7 & 3 & 181.05 & 0.0917 & 2.585 & 1 \\
\hline Isovitexin-xyloside & 564.496 & 14 & 9 & 5 & 239.97 & -1.7961 & 2.540 & 3 \\
\hline Orientin & 448.380 & 11 & 8 & 3 & 201.28 & -0.2027 & 2.572 & 2 \\
\hline artemetin & 388.370 & 8 & 1 & 6 & 96.59 & 3.2086 & 2.360 & 0 \\
\hline aucubin & 346.332 & 9 & 6 & 4 & 149.07 & -2.8015 & 2.844 & 1 \\
\hline agnuside & 466.440 & 11 & 6 & 7 & 175.37 & -1.2312 & 3.019 & 2 \\
\hline Penduletin & 344.319 & 7 & 2 & 4 & 98.36 & 2.897 & 2.283 & 0 \\
\hline Vitexicarpin & 374.340 & 8 & 2 & 5 & 107.59 & 2.9056 & 2.302 & 0 \\
\hline Vitexin & 432.381 & 10 & 7 & 3 & 181.05 & 0.0917 & 2.595 & 1 \\
\hline $\begin{array}{l}\text { Caryophyllene } \\
\text { Tenofovir } \\
\text { disoproxil }\end{array}$ & 204.35 & 0 & 0 & 0 & 0 & 4.7252 & 1.617 & 1 \\
\hline
\end{tabular}

nON: n(hydrogen bond acceptor); nOHNH: n(hydrogen bond donors); Nrot : n(rotatable bonds); TPSA :Total Polar Surface Area; LogP : Predicted octanol/water partition coefficient ; LD50: Oral Rat Acute Toxicity; nVio. :n(Lipinski violation).

The results obtained from ADME analysis with SwissADME and PKCSM (Table 2) reveal that among the tested ligands predicted above, only the Penduletin and the Vitexicaprin fully obeyed the Lipinski's rule of five (molecular mass < 500; Hydrogen-bond donors (HBD) $<5$; Hydrogen-bond acceptors (HBA) < 10; and Log P < 5). However, it exhibits the lowest binding energy. The ligands with the best binding energy, Orientin, and Isovitexin meet only two criteria (molecular mass $<500$ and $\log \mathrm{P}$ ). The Tenofovir disoproxil meets three criteria (molecular mass $<500$ and $\log \mathrm{P}$ and hydrogen, bond donor). 


\section{Conclusions}

This study was conducted to pinpoint the best drug candidates from the set of 10 compounds of Vitex agnus-castus L using molecular docking and ADMET properties. The interaction of the HBV proteins (capside and protein X ) with 10 isolated Vitex agnus-castus $L$. compounds showed that the most stable complex is obtained with Orientin $(-7.1 \mathrm{kcal} / \mathrm{mol})$ and Isovitexin $(-6.9 \mathrm{kcal} / \mathrm{mol})$. Whereas Lipinski's rule of five based on ADME analysis shows that Penduletin and the Vitexicaprin are fully obeyed Lipinski's rule of five. Penduletin and vitexicaprin are the best drug candidates since they have the bests binding energies compared to Tenofovir disoproxil.

\section{Funding}

This research received no external funding.

\section{Acknowledgments}

This research has no acknowledgment.

\section{Conflicts of Interest}

The authors declare no conflict of interest.

\section{References}

1. Ginzberg, D.; Wong, R.J.; Gish, R. Global HBV burden: guesstimates and facts. Hepatology international 2018, 12, 315-329, https://doi.org/10.1007/s12072-018-9884-8.

2. World Health Organization. Available online: https://www.afro.who.int/fr/node/6244 (accessed on $8 / 12 / 2020$ ).

3. Ezzikouri, S.; Pineau, P.; Benjelloun, S. Hepatitis B virus in the Maghreb region: from epidemiology to prospective research. Liver international : official journal of the International Association for the Study of the Liver 2013, 33, 811-819, https://doi.org/10.1111/liv.12135.

4. Baha, W.; Foullous, A.; Dersi, N.; They-they, T.P.; El alaoui, K.; Nourichafi, N.; Oukkache, B.; Lazar, F.; Benjelloun, S.; Ennaji, M.M.; Elmalki, A.; Mifdal, H.; Bennani, A. Prevalence and risk factors of hepatitis $\mathrm{B}$ and $\mathrm{C}$ virus infections among the general population and blood donors in Morocco. BMC Public Health 2013, 13, https://doi.org/10.1186/1471-2458-13-50.

5. Meffre, C.; Le Strat, Y.; Delarocque-Astagneau, E.; Dubois, F.; Antona, D.; Lemasson, J.M.; Warszawski, J.; Steinmetz, J.; Coste, D.; Meyer, J.F.; Leiser, S.; Giordanella, J.P.; Gueguen, R.; Desenclos, J.C. Prevalence of hepatitis B and hepatitis C virus infections in France in 2004: social factors are important predictors after adjusting for known risk factors. $J$ Med Virol 2010, 82, 546-555, https://doi.org/10.1002/jmv.21734.

6. Wasley, A.; Kruszon-Moran, D.; Kuhnert, W.; Simard, E.P.; Finelli, L.; McQuillan, G.; Bell, B. The prevalence of hepatitis B virus infection in the United States in the era of vaccination. J Infect Dis 2010, 202, 192-201, https://doi.org/10.1086/653622.

7. Hansen, N.; Hay, G.; Cowan, S.; Jepsen, P.; Bygum Krarup, H.; Obel, N.; Weis, N.; Brehm Christensen, P. Hepatitis B prevalence in Denmark - an estimate based on nationwide registers and a national screening programme, as on 31 December 2007. Euro Surveill 2013, 18, https://doi.org/10.2807/15607917.es2013.18.47.20637.

8. EASL 2017 Clinical Practice Guidelines on the management of hepatitis B virus infection. Journal of hepatology 2017, 67, 370-398, https://doi.org/10.1016/j.jhep.2017.03.021.

9. $\quad$ Sarin, S.K.; Kumar, M.; Lau, G.K.; Abbas, Z.; Chan, H.L.; Chen, C.J.; Chen, D.S.; Chen, H.L.; Chen, P.J.; Chien, R.N.; Dokmeci, A.K.; Gane, E.; Hou, J.L.; Jafri, W.; Jia, J.; Kim, J.H.; Lai, C.L.; Lee, H.C.; Lim, S.G.; Liu, C.J.; Locarnini, S.; Al Mahtab, M.; Mohamed, R.; Omata, M.; Park, J.; Piratvisuth, T.; Sharma, B.C.; Sollano, J.; Wang, F.S.; Wei, L.; Yuen, M.F.; Zheng, S.S.; Kao, J.H. Asian-Pacific clinical practice guidelines on the management of hepatitis B: a 2015 update. Hepatology international 2016, 10, 1-98, https://doi.org/10.1007/s12072-015-9675-4.

10. Terrault, N.A.; Lok, A.S.F.; McMahon, B.J.; Chang, K.M.; Hwang, J.P.; Jonas, M.M.; Brown, R.S., Jr.; Bzowej, N.H.; Wong, J.B. Update on prevention, diagnosis, and treatment of chronic hepatitis B: AASLD 
2018 hepatitis B guidance. Hepatology (Baltimore, Md.) 2018, 67, 1560-1599, https://doi.org/10.1002/hep.29800.

11. Roemheld-Hamm, B. Chasteberry. Am. Fam. Physician 2005, 72, 821-824.

12. Stojković, D.; Soković, M.; Glamočlija, J.; Džamić, A.; Ćirić, A.; Ristić, M.; Grubišić, D. Chemical composition and antimicrobial activity of Vitex agnus-castus L. fruits and leaves essential oils. Food Chemistry 2011, 128, 1017-1022, https://doi.org/10.1016/j.foodchem.2011.04.007.

13. Sijelmasi, A. Les plantes medicinales du Maroc. Le Fennec éd .Casablanca 1991.

14. Nabih, K.R. Antioxidant activity of different extracts of Vitex agnus-castus (L.) and phytochemical profile. Chemistry 2013.

15. Zhong, H.B.C. State administarion of traditional Chinese medicine of the peopls republic of china. Sganghai Sci technol, press shanghai 1985, 3, 245.

16. Pio-Leon, J.F. Chapter 4-Biological Activities and Phytochemicals of fruits of vitex Plants. In: Bioactive Phytochemicals - Perspectives for Modern Medicine. Gupta, V.K. Publisher: Daya Publishing HouseEditors, Volume 2, 2014; pp. 19.

17. Asdadi, A.; Hamdouch, A.; Oukacha, A.; Moutaj, R.; Gharby, S.; Harhar, H.; El Hadek, M.; Chebli, B.; Idrissi Hassani, L.M. Study on chemical analysis, antioxidant and in vitro antifungal activities of essential oil from wild Vitex agnus-castus L. seeds growing in area of Argan Tree of Morocco against clinical strains of Candida responsible for nosocomial infections. $J$ Mycol Med 2015, 25, e118-127, https://doi.org/10.1016/j.mycmed.2015.10.005.

18. Elmessaoudi-Idrissi, M.; Blondel, A.; Kettani, A.; Windisch, M.P.; Benjelloun, S.; Ezzikouri, S. Virtual Screening in Hepatitis B Virus Drug Discovery: Current Stateof- the-Art and Future Perspectives. Curr Med Chem 2018, 25, 2709-2721, https://doi.org/10.2174/0929867325666180221141451.

19. Morris, G.M.; Huey, R.; Lindstrom, W.; Sanner, M.F.; Belew, R.K.; Goodsell, D.S.; Olson, A.J. AutoDock4 and AutoDockTools4: Automated docking with selective receptor flexibility. J Comput Chem 2009, 30, 2785-2791, https://doi.org/10.1002/jcc.21256.

20. Trott, O.; Olson, A.J. AutoDock Vina: improving the speed and accuracy of docking with a new scoring function, efficient optimization, and multithreading. $J$ Comput Chem 2010, 31, 455-461, https://doi.org/10.1002/jcc.21334. 